Euskal ikerketen aldizkaria | Revue d'études basques |

Revista de estudios vascos | Basque studies review

$17 \mid 2013$

Numéro XVII

\title{
Literatura eta lengoaiaren mugak : Joseba Sarrionandiaren kasua
}

\section{Eider Rodriguez}

\section{OpenEdition}

\section{Journals}

Édition électronique

URL : https://journals.openedition.org/lapurdum/2438

DOI : 10.4000/lapurdum.2438

ISSN : 1965-0655

\section{Éditeur}

IKER

Édition imprimée

Date de publication : 1 octobre 2013

Pagination : 187-199

ISBN : 978-2-86781-409-9

ISSN : 1273-3830

Référence électronique

Eider Rodriguez, «Literatura eta lengoaiaren mugak : Joseba Sarrionandiaren kasua», Lapurdum [Linean], 17 | 2013, Sarean emana----an 15 novembre 2015, kontsultatu 23 juillet 2021. URL: http:// journals.openedition.org/lapurdum/2438 ; DOI: https://doi.org/10.4000/lapurdum.2438 


\title{
Literatura eta lengoaiaren mugak: Joseba Sarrionandiaren kasua
}

\author{
Eider RODRIGUEZ \\ Euskal Herriko Unibertsitatea UPV / EHU
}

\begin{abstract}
:
Ugariak eta arlo askotatik etorritakoak dira lengoaiaren mugen inguruko gogoetak. Geurean, eta literaturaren arlotik, Joseba Sarrionandia bere obra osoan zehar ezintasun hori izendatzen ez ezik ezintasun hori gainditzeko estrategiak erabili dituenetako bat izan da. Halaber, maiz gaztigatu du irakurlea bere testuetan hitzez haratago irakurtzeko aukeraz, esanahi aurrefabrikatuei itzuri egiteko egokitasunaz, eta batez ere, adierazpide izoztuak ahaztu eta hitzei zentzu berri bat ematen saiatu beharraz. Norenak diren hitzak harenak izango baitira esanahiak ere, nork idazten dituen hiztegiak hark aginduko baitu hitz horiek zein errealitate puska ordezkatzen duten.

Lan honen bidez, lengoaiaren mugen kontrako Sarrionandiaren borroka nondik datorren, zein forma hartzen duen eta zertan den aztertu nahi izan dugu.

Hitz gakoak: Sarrionandia/ Lengoaiaren mugak/ Metafora/ Sinboloal Literatura

\section{Sar-hitza}

Sarrionandiak bere lehen liburu argitaratua izan zen Izuen gordelekuetan barrena- ${ }^{1}$ (1981) jadanik agertu zuen Pott bandako kideekin konpartitzen zuen hitzen ahalaren gaineko mesfidantza. Poema liburu honen sarreran nora eza eta etsipena aipatzen ditu idazteko motor gisa, hala nola idazketarekiko fede eskasa; alta, idatzi egingo du. Izan ere, Sarrionandiak bere egiten duen Giorgos Seferisen aipuak adierazten duen legez ("isiltasuna ere ez da zurea hemen non errotako harriak geratuak diren"), isiltasuna ere ez litzateke alternatiba, isiltasuna ere ez baita neutroa, kutsatuta dago, jabegoa dauka. IGBren hondarrean gainera, honakoxea
\end{abstract}


dio Samuel Becketten ahotik: "Zer adierazirik ez, zertaz adierazi ere ez, nundik adierazterik ez, ezin adierazi, adierazi nahi ere ez, adierazteko halabeharrarekin batera". Bere poetikaren ardatzetako bat izango denaren aurrean gaude, bere obra osoan zehar eta forma ezberdinen pean agertuko den ardatza.

Gartzelako poemak²-en (1992) "finean, hitza/ hutsik geratzen den zelda/ besterik ez da" eta "hitzek esan nahi dutena geroago/ eta gutiagoa diotenean" irakur daiteke, eta Hnuy illa nyha majah yahoo-n (1995) Sarrionandiak "errima artifizialei" eta "tropo zikinei" erakutsi mesfidantza berresteaz gain "amour eta toujours lako errimak zaborretara" botatzearen alde egiten du, hala nola "poesia egitea ez da gauza itzela, lengoaia/ ber egitearen joko hutsala" dela oroitarazten.

Lagun izoztua $a^{3}$-n (2001) gormutuen alfabeto bat aurki daiteke paratestuaren osagarri, zeinari buruz honela dioen LI-ren karietara eskaini elkarrizketa batean: "Gormutuen alfabetoaren aipamena hor adierazgarria denaren eta ez denaren muga seinalatzera doa. Gainera, nobelako pertsonaiok apur bat gormutuak dira, ez? (EEDA, 2001)". Alfabeto honek zuzenean garamatza eleberriko protagonistarengan pentsatzera: izoztu egin da, ezin du hitzik egin, kontatu, esan, adierazi. Nolabait ere bere poetikan tai gabe agertu den esan ezintasunaren edo ezin adieraziaren gaia zertzen du izoztutako pertsonaia honek, IGB argitaratu eta hogei urte geroago.

\section{Joseba Sarrionandiaren abisua: hitzak ez dira diruditena}

Nietzschek esaten zuen lengoaian ez dagoela arrazoirik, lengoaia atso zahar engainatzailea dela, eta gramatikaz sinesten jarraitzen dugun artean ez dugula Jainko ideia uxatuko, hau da, ez ditugula geure muga hestuak gaindituko ${ }^{4}$.

Sarrionandiak gaztigatu du bere irakurlegoa hitzen bestaldean irakurtzeko aukeraz, zentzu aurrefabrikatuen mundutik ihes ${ }^{5}$ egiteko egokitasunaz, adierazpide izoztuak ahaztu eta gauzei, lengoaiari batez ere, beste zentzu bat aurkitzen entseatu beharraz ${ }^{6}$. Hitzak ez baitira neutralak, "hitzak, guri ailegatzen zaizkigun hitzak, historiaz kargaturik ematen zaizkigu, iadanik, eta zama zahar eta astun horrek harrapatzen gaitu geu ere"7.

NENH-n (168-169) beste modu batera jasotzen da Sarrionandiak eginkizun propiotzat daukan hau, tribuaren hitzak emendatzea, gezurrezko hitzen atzean egiazkoagoak direnak bilatzen ahalegintzea, botereak "hildako" mintzaira berpiztea, bizi berri bat ematea:

Poetaren eginbidea, Stéphane Mallarmé hark esan zuenez, tribuaren hitzei zentzu garbiago bat ematea da. Zentzu garbiagoa, osoagoa, irekiagoa, hitzen bidez kontzientziaren eta munduaren artean erlazio aproposagoak sortzeko. Eta hitzen bidez, gauzen eta situazioen

\footnotetext{
2.- Aurrerantzean GP.

3.- Aurrerantzean LI.

4.- Sarrionandia, Ni ez naiz hemengoa (1985): 163; aurrerantzean NENH.

5.- Ibid.: 26.

6.- Ibid.: 25 .

7.- bid.: 31 .
} 
ezagumen argiago eta berriak lortzeko. Poesiaren objetoa bizitza da, eta mundua, gure lurreango bizitza, erdi ezagun erdi ezezagun daramagun bizitza hori. Gure lengoaia baldresa emendatzen entseiatzen bagara, hitz egiazkoagoak erideiten ahalegintzen bagara, zihurtasun faltsoen mugak desegiteko, lurreango gure bizitza hobeto ezagutzeko eta, ezagutzeaz, atsegin hartzeko da.

Sarrionandiaren azken literatur lana izan den Moroak gara behelaino artean? ${ }^{8}$ (2010) saiakera mardula abian jartzen duen fraide frantziskotarra amazigheraren gramatikaren xerka aurkezten zaigu, bestea ${ }^{9}$-ren gramatika ezagutzera, bestea ulertzera eta errelatatzera, eta bestea, kasu honetan, euskalduna izan daiteke MGBA? osoan zehar iradokitzen den paralelismoa erabilita.

Gramatika bestea ulertzeko, errelatatzeko eta zergatik ez, botere harremanak ezartzeko (menperatzeko zein subordinaziotik askatzeko) tresna gisa aurkezteak zuzenean garamatza LI-ko idazle fedegabeko etsituarekin lotura egitera, zeinari dagoeneko motz gelditu baitzaio "tesia, antitesia eta sintesia" triada dialektikoa, eta horregatik triada berria asmatu du: "tesia, antitesia eta sintaxia". Gramatika eta sintaxi berriak mintzaira berri bat berrasmatzeko alegia; hitzen jabegoa hankazgoratu egin baitaiteke, hankazgoratu egin behar baita, edo MGBA?-eko hitzaurrean esaten zaigun legez: "leitu dezakezu edo ez leitu. (...) Idatzita dago. Baina ez dizut mektub ${ }^{10}$ esango, moroek esaten duten zentzuarekin. Idatzitakoa ere emenda daiteke. Idatz dezakezu gainean. Dena egiteko dago oraindik".

Eta berriz ere Sarrionandiaren obra zeharkatzen duen ideiarekin egingo dugu topo: hitzek ez dute zertan itxuraz esan nahi dutena esan nahi, emendatu daitezke, berridatzi, emendatu behar dira, berridatzi.

Nola egituratzen da baina tribuaren hiztegi berri hau? Zein eite dauka hitzen emendatzeak? Nola berridazten da hizkuntza bat? Nola desidazten da? Sarrionandiaren obra osoaren hondoan helburu hau aurki bagenezake ere, sinboloak, metaforak, alegoriak eta hiztegiak aipa genitzake egikaritze honen forma ikusgarri nagusitzat: izan ere, Sarrionandiak, batetik, Hitzen ondoeza ${ }^{11}$ (1997) hiztegiaz gain, Gau ilunekoak ${ }^{12}$ (2008) alegoria eta bere poesia eta narrazio liburuetako sinboloak eta metaforak baliatuko ditu iraganetik datozen hitzen, testuen eta sinboloen bulkada profitatu eta hitz, testu eta sinbolo horiek esanahi berriz janzteko.

Ikus ditzagun, banaka, lengoaiaren mugei aurre egiteko Sarrionandiak erabilitako

8.- Aurrerantzean MGBA?

9.- Okariz (2012): "Los moros no existen, porque nadie se autodefine como moro. Uno es árabe, el otro es bereber, moro es lo que le dicen. O sea, el moro es el otro por excelencia, desde los cruzados y el testamento de la reina Isabel hasta el choque de civilizaciones de Samuel Huntington. Es el fanático, el peligroso, el inmigrante, el terrorista. Es la gente marcada por sobredeterminaciones del calibré de Alá, el Estado, la Economía y demás, al punto de que la convivencia normal se le pone difícil, y en que ni siquiera su propio comportamiento puede ser ético y benévolo. La idea es que los homosexuales, los chechenos, las mujeres, los inmigrantes, los vascos, los negros, casi todos somos moros en algún sentido".

10.- "Idatzita zegoen" esan nahi du eta gertaeren fatalitatea adierazteko esaten dute magrebtarrek.

11.- Aurrerantzean $\mathrm{HO}$

12.- Aurrerantzean GI. 
ihesbide nagusiak zein diren.

\section{Ihesbide bat: metaforak}

Literaturak zeinuak ditu euskarri, hitzak. Hitzek, hots bitartez edo idatzizko zeinu bitartez entitate bat edo entitate multzo bat adierazten dute. Baina batzuetan, hitzok ez dira nahikoak entitatez osatutako mundua azaltzeko edota estaltzeko, eta orduan, material horrekin, hitzak diren segmentu mugatu horiekin, jolas berriak asmatzen dira. Batzuetan, jolas horiek hitz konbinazio ezohikoetan dute oinarri. Beste batzuetan, hitzen desagerpenean edo hitzen errepikapenean konnotazio eta are esanahi berriak aurki daitezke. Zenbaitetan a priori tolesdurarik ez duen hitz edota hitz konbinazio horrek aurrez idatzitako literatur ondare oso batekin jarriko gaitu harremanetan, a priori-zko esanahi horren geruzaren azpitik beste hamaika agerraraziz... Hitz jolas guztiek izena dute. Edo hobe, hitz jolas guztiek izena edukitzea nahi genuke, hain da handia gizakiaren tema ingurua klasifikatzeko. Antzinatik, Erretorika eta Poetika arduratu dira zeregin horretaz. Gaur egun ordea, diziplina ugari saiatu dira tropoen edota figura literarioen taxonomia hobetzen eta zabaltzen. Hala ere, zaila da adostasunetara iristea, dena delakoa izanda diziplina, paradoxa errepikakor batekin aurkitzen baita: hitzez sortutako materiala hitzak diren materialaz azaltzeko beharra.

NENH-n Sarrionandia Nietzscheren bitartez lengoaiaren mugak gainditzeko moduez mintzo zaigu, lengoaia metaforikoa erabiltzeaz alegia:

Nietzschek lengoaia metaforikoa proposatzen zuen bere ontologian. Bere ustez, kontzeptoen lengoaia dogmatikoa ez da errealitatearen aldaketa eta osotasuna guziz hatzemateko gaia. (...) Ezagumen zientifikoa, iadanik, materiala ezik sinbolikoa da ${ }^{13}$.

Lengoaiaren ahitzeaz eta mugez hain sinetsita dagoen idazle batentzat ihesbidea da lengoaia metaforikoaren erabilera, dagoenetik, hitzen esanahi "ofizial"etik abiatuta (hitzen esanahi entziklopedikoaz gainera, hitz horiek duten karga historikoaz ari gara), esanahi ehundura berria josteko egokiera ematen baitio.

Aristotelesen (1974) arabera "metafora, termino metaforikoa eta errealaren arteko antzekotasunari esker gertatzen den lekualdaketa, ordezkapen, zein konparazio eliptiko" bat da. Nabardurak gorabehera, definizio hau indarrean mantendu da ia gaur egunera arte: Ciceronek Orator lanean eta Quintilianok Institutio Oratoria-n zentzu berean erabili zuten.

Paul Ricœurrek (1980) honela laburbildu zuen mundu klasikoak metafora ulertzeko zuen manera:

1.- Metaforaren erretorikak hitza erreferentzia unitatetzat dauka. Definizioan, izen bat edo aditz bat aipatzen da.

2.- Lekualdatze batean datza: hitz bat, egoki betetzen duen leku batetik ez dagokion beste batera iragatea. 
3.- Lekualdatzeak hitzaren esanahiaren zabaltzea dakar. Lekualdatutako hitzak erabilera kodifikatua dauka, zeina lekualdatzen baita erabilera edota esanahi ezberdin baina jatorrizkoarekin loturiko bat betetzen duenean.

\section{4.- Fenomenoaren azalpena ordezkapenaren teorian datza.}

Metafora Erretorikaren tresna izateko sortu zen arren berehala baliatu zuten poetek (Gorgiasek, adibidez) beren testuak ontzeko (Pujante, 2003: 208). Ricœurren iritziz (1980) Aristotelesek berak abiatu zuen metaforaren taxonomia nahasia: izan ere, metafora kontzeptua Ars rhetorica-n jasotzeaz gain Ars poetica-n ere jaso baitzuen, eta bikoiztasun honetatik dator metafora zedarritzeko zailtasuna. Diziplina arteko gurutzaketa hori nahasgarria da eta kontrakarrean gertatzen da, eta hortik, ezin adituak definizio bakar batera bildu: batetik, metafora ornato erretorikoa den aldetik, haren helburua pertsuasioa da; bestetik, metafora literaturaren erreminta den aldetik, haren helburua giza ekintzen mimesia lortzea da. Ildo honetan mintzo da Max Black (1966): metaforarik ezean munduaren zati bat esan gabe geldituko litzateke, metaforek, hitzak iristen ez diren lekuraino iristeko gaitasuna baitaukate.

Bai erretorikaren esparruan eta baita poetikarenean ere, metafora, egikaritze estatikotzat hartua izan da. Gaur egungo ikerketen norabidea ordea kontrako bidean doa ${ }^{14}$. ikuspegi taxonomiko klasikoaren zabarkeria azaleratu eta ordezkapenaren teoria gaindituta gelditu da. Teoria berrien funtsa metaforek pentsamendua eraikitzen eta gure pentsagaitasuna determinatzen dutela da. Pujanteren arabera, Ivor Armstrong Richards izan zen halako planteamendua egin zuen lehena: "[metafora] ez da apaingarri bat, ez da desbideratze emotibo bat, adierazkortasun behar ordezkaezin bat da".

Lakoffek eta Johnsonek (1991) koska bat gehiago estutu zuten metaforaren kontzeptualizazioa metaforaren sistematizazioari buruz aritzerakoan ("Gure hizkuntzaren adierazpen metaforikoak sistematikoki daude loturik kontzeptu metaforikoekin"). Honela, kontzeptu metaforikoa sistematikoa denez, kontzeptuaren alderdi horri buruz mintzatzeko erabiltzen dugun hizkuntza ere metaforikoa da.

Pujantek dio guztiz ezinezkoa dela metaforaren azterketa ahitzea, eta horren erakusgarri Van Noppen eta Holsen Metaphor II. A Classified Bibliography of Publications from 1985 to 1990 liburua, zeinean aintzat hartutako bost urteko tartean 3500 erreferentziatik goiti aztertzen diren (Pujante, 2003).

Idazle batek baino gehiagok ezin izan dio eutsi metafora den katramila askatzeko tentazioari. Borgesek (2007), adibidez, literaturaren historia metafora bakar batzuen historia besterik ez dela dio: erreka-denbora, bizitza-ametsa, begiak-izarrak, emakumeak-loreak... Eta mendebaldarrontzat, metaforarik gabeko literatura bat irudikatzea gaitz xamarra den arren, Borgesek ekialdeko poesiagintzaren etsenplua jartzen digu begien parean: metaforarik erabili gabe mendeetan zehar gure garaietaraino iritsi diren haikuak, adibidez.

14.- Ez beti, hala ere: bai Gérard Genettek eta bai Tzvetan Todorovek ere, antzinako norabidean eraiki zituzten euren definizioak: Genettek adierazpen normala eta adierazpen figuratua kontrajarri zituen; Todorovek zentzu propioa eta zentzu lekualdatua (Pujante, 2003: 208). 
Lugones ${ }^{15}$ pensó que la metáfora era esencial para la poesía y, sin embargo, hasta donde yo sé, no se encuentran metáforas -o apenas una insinuación y nunca la metáfora declarada- en la poesía china y en la japonesa. No hay metáforas, según recuerdo, mientras que en el caso del inglés antiguo, por ejemplo, la poesía está hecha de metáforas. Así, cuando llaman al mar "la ruta de la ballena", la vastedad de la ballena sugiere la vastedad del mar; y al mismo tiempo, en contraste, cuando lo llaman (al mar) "camino del cisne", en un cisne infatigable dan la extensión del mar propiamente dicho.

Sarrionandiaren poesia eta prosa metaforaz kargaturik daude eta adibiderako kasik bere edozein olerkik balio diezaguken arren "Ene begiek ez dute malko isuritzeko gogorik" hautatu dugu, metaforek duten indar eta edertasunagatik ${ }^{16}$.

Ene begiek ez dute malko isuritzeko gogorik/ Denik eta bizitza bakarra bizi dutelako. Entzun, / Astiro doa denbora, idi gorrien gurdi hori./ Begira, erlojuetako orratzak unean uneka herdoiltzen./ Zenbat gauza utzi dugun estrata bazterretan/ Edo laku urdinen hondoan, bizitza bakarrean,/ Eta zenbat aldiz galdu garen behelainotan/ Basoilar izateko ametsetan dabiltzan kurloiekin./ Gure desirak ez dira jada habia abandonatuak besterik/ Gure bihotzetan. Eguzkia gurpil ahula da./ Ez entzun, ez begiratu, ez pentsatu gehiago,/ Bizitza bakarra delako. Gal ez dadin, ibili ez/ Eta sentitu ere ez, harriak lez izan nahi nuke,/ Mendea eta segundoa gurutzatzen diren lekua,/ Lekua besterik ez izan, urrin deritzan aberrian.

Sarrionandiak espetxealdian idatzitako poema honek espetxeak sorrarazten dion mina jasotzen du, espetxea eta espetxearen inguruko hitzik behin ere aipatu gabe, "espetxe" eta "mina" bezalako hitzak agortuta baleude bezala. Honela, kondenaren zama ondoko hiru metaforetan gutxienez aurki daiteke adierazita "denbora, idi gorrien gurdi hori", "erlojuetako orratzak unean uneka herdoiltzen" eta "erlojua, gurpil ahula da". Eta bakardadea jasotzen du "gure desirak ez dira jada habia abandonatuak besterik" metaforak eta inpotentzia adieraz lezake "zenbat aldiz galdu garen behelainotan/ basoilar izateko ametsetan dabiltzan kurloiekin" metaforak.

Halaber, Sarrionandiaren obran ugariak dira itsasoarekin eta bidaiarekin loturiko metaforak, bai poesiazko lanetan eta baita prosazkoetan ere. Hain dira ugariak eta errepikakorrak, hain dute presentzia handia bere lehen lanetik azkenera bitarte ezen eta bidaiaren eta itsasoaren ${ }^{17}$ metaforek testu paralelo bat osatzen dutela esan baitezakegu, lehena Sarrionandiaren militantzia politikoaz hitz egiteko, bigarrena gatazka politikoaz bere osotasunean jarduteko. Gure ustez, zentzu honetan berreskuratzen du Sarrionandiak Barthesen aipu hau: "Testo hitza textus hitzetik dator, texere aditzaren partizipio iraganekotik, ehundu

15.- Leopoldo Lugonesen (1999) Lunario sentimental lanaz ari da.

16.- Olerki hau lehen aldiz Fernando Pessoaren Marinela (koadro bakarreko drama estatikoa) (1985) Sarrionandiaren euskarazko aldaeraren epilogoaren oharrean aurki daiteke, eta poema honen beste bi aldaera aurki daitezke Marinel Zaharrak-en (1987) eta GP-en (1992).

17.- Eta bidaiaren eta itsasoaren alorreko terminoek, hala nola, lehengoarekin loturiko maleta eta trena, adibidez, eta bigarrenarekin loturiko ontzia eta naufragoa kasurako. 
esan nahi baitu: esanahi lotuen oihal bat da testoa"18. Balirudike egileak esanahien sarearen ideia hau bere irakurlegoarengan txertatu nahi duela, nolabait ere bere testuen irakurketa sakonagoak egitera bultzatu aldera:

Izan ere, ezin da esan mitologia grekolatinoa, edo Erdi Haroko teatro erlijiosoa, edo Ameriketako literatura, edo fisika kuantikoa gureak ez direnik. Geureturik ditugu, geureak ere badira kultura unibertsalaren partaide garen heinean. Gure euskal tradizioaz gainera, tradizio unibertsalaren oinordeko gara ${ }^{19}$.

Eta hiru urte geroago argitaratutako Marginalia (1988) saiakera liburuan berriz ere aurkituko dugu ideia hau:

Imajinazioa -Charles Baudelairek esan zuenez- giza ahalmenik zientifikoena da, analogia unibertsala konprenitzen duelako. Suomitar Kalevalako konparazio kargatu eta harrigarriek, euskal kopla zaharretako ekibalentziek, edota Janis Joplinen kantetako metaforek eta Bernardo Atxagaren poemetako imajinek ustekabeko eta argizgaindiko erlazio sare sekretu hura berreraikitzen dute.

"Sare sekretu" honen parte dira Sarrionandiak hain maiteak dituen testuarteko jolas ugari, hala nola, bidaiari eta itsasoari eginiko erreferentzia guztiak ere. Izan ere, Sarrionandiaren bidaiaren eta itsasoaren esanahi sarea ez baita neutroa, independentea eta iraganik gabea. Haatik, Sarrionandiaren "bidaia" eta "itsasoa" historiaz kargaturik daude eta historia horretan bertan txertatzen dira Sarrionandiak hitzoi ematen dizkien esanahi berriak ere.

\section{Bigarren ihesbidea: sinboloak}

M.H. Abramsen (1971) literatur terminoen glosarioan, Symbol sarreraren ondoan, hauxe irakur daiteke:

Sinbolo bat, zentzurik zabalenean, zerbait gehiago esan nahi duen zerbait da; zentzu honetan, hitz guztiak sinbolo dira.

Beraz, sinboloaren gaineko ikuspegi zabal honek dioenaren arabera, sinboloak, ageriko esanahiaz aparte, beste esanahi bat ere badu. Honela jarraitzen du:

Some symbols are "conventional" or "public"; thus "the Cross", "the Red, White and Blue", "the Good Shepherd" are terms that signify symbolic objects of which the further significance is fixed and traditional in a particular culture. Poets, like all of us, use such conventional symbols; many poets, however, also use "private" or "personal symbols", which they develop

18.- NENH: 27.

19. Íbidem.: 130. 
themselves. Often they do so by exploiting preexisting and widely shared associations with an object or action -for example, the general tendency to associate a peacock with pride and an eagle with heroic endeavor, or to associate climbing with effort of progress and descent with surrender or failure. Some poets, however, often use symbols whose significance they mainly generate for themselves, and these set the reader a more difficult problem in interpretation.

Hau irakurriz, ondoriozta daiteke:

1.- Sinboloa jende arruntak ez ezik poetek ere baliatzen dutela.

2.- Poetek baliatzen dituzten sinboloen artean mota bat baino gehiago dagoela, eta hiru behintzat sailkatu daitezkeela: a) sinbolo konbentzionalak, b) poetak garatzen dituen sinbolo pertsonalak, c) poetak sortu eta irakurleak nekez interpreta ditzakeen sinboloak.

3.- Interpretatzen zailena c tipoko sinboloa dela, eta ondorioz, sinboloak interpretazioa eskatzen duela.

Aitzitik, Abramsen definizioa, duen zabaltasunagatik motz gelditzen zaigu: motz, ez duelako sinboloaren funtsa jasotzen; zabal, ez dituelako sinboloaren mugak nahikoa zedarritzen. Zaila da sinboloaren definizio zehatz batera iristea. Batetik, sinboloa alderdi askotatik izan delako aztertua: Psikoanalisiaren bidetik Freudek, Lacanek eta Jungek baliatu eta aplikatu izan dute; Bachelardek sinboloen irakurketa oso berezi eta pertsonala egin zuen fenomenologiaren eta psikologiaren mugatik; Levi-Straussek eta Durandek antropologiaren argitan aztertu izan dituzte sinboloak; Eliadek, sinboloak eta mitoak lotu izan ditu zeresan handia eman duten lanetan; eta Dumezilek eta Fryek, mitokritikatik, azterketa sakonak egin dituzte sinboloa eta mitoa harremanetan jarriz.

Rafael Argullolek (1991) etimologiara jotzen du sinboloaren funtzioa ulertzeko argi bila:

¿Qué quiere decir símbolo? Es, en principio, una palabra técnica de la lengua griega y significa «tablilla de recuerdo». El anfitrión le regalaba a su huésped la llamada tessera hospitalis; rompía una tablilla en dos, conservando una mitad para sí y regalándole la otra al huésped para que, si al cabo de treinta o cincuenta años vuelve a la casa un descendiente de ese huésped, puedan reconocerse mutuamente juntando los dos pedazos. Una especie de pasaporte en la época antigua; tal es el sentido técnico originario de símbolo. Algo con lo cual se reconoce a un antiguo conocido.

Sarrionandiak pentsamendu sinbolikoari buruzko Joan Huizingaren aipu bat jaso zuen NENH-n, gure ustez haren sare sinbolikoa argitzen lagungarri izan daitekeena:

Joan Huizinga jakintsuaren ustez, pentsamendu sinbolikoa pentsamendu primitibo edo arkaikoaren ezagugarria da (...) Pentsamendu sinboliko basatiena, haurrena, mistikoena eta poetena da, baina sinbolizazioa ez da arbitrarioa eta aldakorra, sinbolizaziorako ez da heldutasun falta suposatu behar, ezen sinbolizazioan intuizio sakona baitago beti. Oreka eta 
anbiguitatea, imajinazioa eta lausotasuna daude beti sinbolismoan, lotura erreal eta esentziala dago beti erlazionatzen diren gauza bien artean ${ }^{20}$.

Huizingak aipatu eta Sarrionandiak erreskatatzen duen "intuizio" hori ezagutzarekin eta tradizioarekin lotzen dugu. Testu bat objektiboki irakur ezin daitekeen bezala, ezin da sinbolo bat objektiboki "irakurri". Horrela, eta adibide bat jarrita hobeto ulertuko delakoan, "itsasontzi" irakurritakoan tradizionalki "itsasontzi"ak ordezkatu duen horren (komunitatearen ideia, heriotzaren barkua, ugalkortasuna, abentura...) inguruko ezagutza aktibatu egingo da eta aurrean dugun "itsasontzi" horren esanahi sinbolikoari eragingo dio, Harreraren Estetikatik hartutako termino bat erabilita, sinbolo horren determinazio prozesuari eragingo lioke. Itsasoaz eta bidaiaz gain, Sarrionandiaren obran maiz agertzen diren beste sinbolo batzuk dira: batetik, "hondartza", atseden eta plazeraren leku izateaz gain, Establishment-aren eta bizimodu burgesaren oholtza ere izan daitekeena, itsas bizitzaren kontrapuntua, hain zuzen ere; bestetik, "izotza"k erbestaldia ordezkatzen du, bertan bizitzea kosta egiten da eta itsasoak ordezkatzen duen borrokaldia ez den eta hondartza den pausalekua ere ez den espazioa marrazten du.

Umberto Ecok (2002: 152) aitortzen du dagoeneko sinboloa zer den ez dakiela eta metaforaren eta sinboloaren arteko bereizketa argia egiten du:

No pertenece al orden de lo simbólico la metáfora. (...) No creo que suceda lo mismo con el modo simbólico, que, como veremos, oculta su potencial de sentido precisamente detrás de la apariencia engañosa de una inexplicable obviedad. (...) (Eco, 2002).

Esan beharra dago, posible dela Sarrionandiaren prosazko eta poesiazko lanetan barneratu ahala hitz berberak metafora izaera izatea batzuetan eta sinbolo izaera besteetan. Bestetzuetan gertatuko zaigu aurrean dugun hitza interpretagarria den, lengoaiaren mugak zabaltzeko dagoen ala ez ebatzi ez ebatzi zalantza egingo dugula. Nola jakin dezakegu sinbolo bat dela aurrean gaudela eta ez interpretatu behar paranoide batek hartuta? Ecok ondoko gakoak ematen digu:

La sugerencia nos la ha dado, hace algún tiempo, un apasionado y necesariamente determinado buscador de sentidos segundos: Agustín. Cuando algo, en las Escrituras, aun presentándose como semánticamente comprensible, nos parece fuera de lugar, excedente, inexplicablemente insistido, ahí es preciso buscar un sentido segundo que se esconde. La atención hacia el modo simbólico nace de la constatación de que algo hay en el texto, que tiene sentido, y aun así habría podido no estar, y nos preguntamos por qué está. (Eco, 2002: 167).

Todorovek (1982) pertinentzia printzipioa deitu zion honi, sen ona esaten dio Ecok.

LI-ko itsasoak, adibidez, sinboloaren ordenaren baitan egongo lirateke, aldiz, Izuen gordelekuetan barrena-ko lehenengo hitzaurreko itsas irudiak orden metaforikoari legozkioke, hala nola, bere poesia liburuetako itsas irudi gehienak ere. 


\section{Hirugarren ihesbidea: alegoriak}

Mundu klasikoan, sinboloa eta alegoria sinonimotzat zituzten. Gaur egun, ordea, alegoriak kodifikazio itxi baten parte dira, ez aitzitik, sinboloak. Honela azaltzen du Ecok:

No entra en el orden de lo simbólico la alegoría, donde el doble significado no brota de la homonimia sino de la codificación casi heráldica de algunas imágenes (Eco, 2002).

Izan ere, alegoriak, sinboloak ez bezala, kodifikazio itxi baten parte dira, aitzitik Sarrionandiak ez dio muzin egiten hauek erabiltzeari hitzen "berezkotasuna" gainditu eta zabaltzeko. Horrela uler daiteke GI narrazioa, zeinean, Azkorbebeitiak (2008) ${ }^{21}$ azpimarratu bezala, "segituan sortzen da trasposizioa egiteko tentazioa. Beste klabe batzuetan ere irakur daiteke, eta idatzita dagoen moduan idatzita dagoelako sentitzen dugu tentazio hori". Izan ere, Baionan legez kanpoko immigrante delakoan atxilo hartu duten norbaiten "beste planeta" bateko bizipenak kontatzen ditu liburuxkak. Beste planeta hartan "ez da eguzkirik inguruan, ez da gauaren ondoan egunik", kolorerik ere ez zen ezagutzen, eta bertakoak jaio, bizi eta hil egiten ziren, iluntasun erabatekoan, eta gizaldi bakoitzean bizpahiru aldiz agertzen ziren izarrek argia eman zain egoten zen bertako jendea. Hau irakurrita, kosta egiten da narrazioan aurrera egitea argiak edo izarrek ordezka lezaketenaren inguruko hipotesietan abiatu gabe, alegia, argia eta izarrak bezalako elementuen esanahi alegorikoak aurkitzeko saialdirik egin gabe. Izan ere, kasik ezinbestekoa suertatzen baita GI-en irakurketa abiatu bezain pronto Platonen kobazuloaren alegoriarekin lotura ez egitea eta ilunpetan preso bizi den jendearen nortasunak galdezka egitea (geu ote gara?, haiek ote dira?), hala nola, argi bila joateko saialdiak zein izan diren edo izan daitezkeen itaun egitea, adibidez.

\section{Laugarren ihesbidea: hiztegia}

Lewis Carrollek idatzi eta Sarrionandiak (1985a:162) jasotako dialogo miresgarriak seinalatzen du Sarrionandia hainbeste arduratzen duen hizkuntzaren mugen gakoetako bat, hain zuzen ere, hitzen jabetzaren ingurukoa:

-Nik hitz bat esaten dudanean -esan zuen Humpty Dumpty hark- neuk adierazi nahi dudana esan nahi du, ez gehiago ez gutiago.

-Arazoa -esan zuen Alizek- hau da, ea hitzek hainbeste gauza desberdin adieraz dezatela lor dezakezun.

-Arazoa -ihardetsi zuen Humpty Dumptyk- ea nork agintzen duen jakitea da arazo guzia.

21.- Azurmendi (2008). 
Norenak diren hitzak, harenak izango baitira esanahiak ere. Nork idazten dituen hiztegiak, hark aginduko du hitz haiek zein esanahiz bete. Hitzen esanahi "ofizial" horren ordaina izan baitaiteke "hitzei botereak ematen dien esanahia", eta ondorioz, hitzak esanahi eta irakurketa ez ofizialez betetzeko lana boterearen kontrako lan gisa ere uler genezake, inertziaren kontrako, ezarriaren kontrako borroka. Honela "hitzei botereak ematen dien esanahia"ri aurre egiteko saiakera gisa uler daiteke HO hiztegi pertsonala. Potteko kideek eta bereziki Sarrionandiak hain maitea zuen Ambroise Bierceren (2000) Deabruaren hiztegia-ren uberan idatzitako lan honen hitzaurrean honelaxe dio iurretarrak:

Ondoko hitz hauek gure tribuaren hizkera sendatzeko edo indartzeko balio badute, ondo. Baina gure tribuaren hizkera hobetzea ez ba dakarte, orduan, aspaldiko gure ondoez orokor hau gehi dezatela.

Tribuaren hitzak emendatzea, gezurrezko hitzen atzean egiazkoagoak direnak bilatzen ahalegintzea, botereak "hildako" mintzaira berpiztea, bizi berri bat ematea. Izan ere, ia mila sarreren bidez, higatutako hitzak argi berritan irakurtzeko aukera ematen dio Sarrionandiak irakurleari:

\section{ABERTZALEAK}

Euskal Herrian, politikazko gauzak hain daude ilun, eta euskaldunak beren herriaren independentziari ala dependentziari buruz hain sinesgaitz eta zalantzan ze, ematen du inor abertzale denean, "a ber..." sarritan esaten duelako dela ${ }^{22}$.

\section{GOBERNUAK}

Gure herriko baserrietan horrela entzuten zen:

-Behiak gobernatzera noa...

Eta esnea jeistera edo dena delakora sartzen zen, baserritarra, ikuilura.

Geroztik ezagutu ditudan "gobernuak" ere jabeen abereekiko harremanen antzekoak iruditu zaizkit ${ }^{23}$.

\section{ISILTZEA}

Errime esanda ez, baina apalago esanda "isilik" esaterakoan "hitz hilik" esaten dela ematen $\mathrm{du}^{24}$.

$\mathrm{HO}, 12$.

$\mathrm{HO}, 364$

HO, 492. 


\section{Ondorioak}

Literaturaren eta lengoaiaren mugen inguruko gogoetak arlo diziplina eta ertz ugarietatik egin direla aipatu dugu, halaber, muga hauek gainditzeko asmatu jolasak taxonomizatzeko zailtasunak izan ditugu aipagai. Muga eta zailtasun hauek euskal idazle baten argitan ikusi nahi izan ditugu, Joseba Sarrionandiarenean, hain zuzen ere.

Sarrionandiak metaforak, sinboloak, alegoriak eta hiztegiak erabili izan ditu agortuta, mugatuta eta instituzionalizatuta sentitzen zuen lengoaia iraultzeko eta errealitatearen inguruan libreago hausnartzeko. Obraz obra berritu duen saialdi honen bitartez, bere testuen gaineko irakurketa posibleak ugaritzearekin bat, irakurleari sortzaile izateko aukera handitzen zaie, izan ere, Sarrionandiaren lanak tentuz irakurtzen dituen orok hitzen mugez haratagoko ateak zabaltzeko gonbidapena aurkituko du.

\section{Bibliografia Orokorra}

ABRAMS, M. H., 1971, A Glossary of Literary Terms, New York, Holt, Rinehart and Winston, inc.

ARGULlOL, R., 1991, (sarrera) in Gadamer, H.R., La actualidad de lo bello, Barcelona, Paidós. ARISTÓTELES, 1974, Poética, Madrid, Gredos.

AZURMENDI, N., "Gau ilunekoak idatzi du Joseba Sarrionandiak, "biderkatzeko gaitasuna duen liburu bitxia"', Diario Vasco, 2008-XI-15.

BIERCE, A., Deabruaren hiztegia, Bilbo, Ibaizabal, 2000.

BLACK, M., 1966, Modelos y metáforas, Madrid, Tecnos.

BORGES, J.L., 2007, "La metáfora", New Orleansen 1982an emandako hitzaldia, http://loslaberintosdeltiempo.blogspot.com/2007/10/borges-y-la-metfora.html-etik hartua. ECO, U., 2002, Sobre literatura, Barcelona, RqueR.

1.EGILERIK EZ DA AGERI, 2001, "Angustia eta konfusio handiarekin idatzi dut nobela", Argia, 2001-11-18, 1830 zenbakia.

LAKOFF, G. \& JOHNSON, M., 1991, Metáforas de la vida cotidiana, Madrid, Cátedra

2. OKARIZ, L.M., "Todos somos moros de alguna manera", Noticias de Álava, 2012-XII-

3. PUJANTE, D., 2003, Manual de retórica, Madrid, Castalia Universidad.

RICCEUR, P., 1980, La metáfora viva, Madrid, Ed. Cristiandad.

4. TODOROV, T., 1982, Simbolismo e interpretación, Caracas, Monte Ávila Editores.

\section{Joseba Sarrionandiaren sorkuntza lanak}

SARRIONANDIA, J., 1981, Izuen gordelekuetan barrena, Bilbo, Bilbo Aurrezki Kutxa.

—, 1983, Narrazioak, Donostia, Elkar.

—, 1985a, Ni ez naiz hemengoa, Donostia, Elkar.

—, 1995b, Marinela. Kuadro bakarreko drama estatikoa [Fernando Pessoaren O’Marinheiro], Zarautz, Susa.

—, 1986, Atabala eta euria, Donostia, Elkar.

—, 1987, Marinel zaharrak, Donostia, Elkar.

_, 1988, Marginalia, Donostia, Elkar. 
—, 1989, Ez gara gure baitakoak, Iruñea, Pamiela.

—, 1990, Ifar aldeko orduak, Donostia, Elkar.

_, 1992a, Gartzelako poemak, Zarautz, Susa.

—, 1992b, Han izanik hona naiz, Donostia, Elkar.

—, 1995, Hnuy illa nyha majah yahoo (Poemak 1985-1995), Donostia, Elkar.

—, 1997, Hitzen ondoeza, Tafalla, Txalaparta.

—, 2001, Lagun izoztua, Donostia, Elkar.

—, 2003, Kolosala izango da, Tafalla, Txalaparta.

-, 2004, Akordatzen, Tafalla, Txalaparta.

—, 2008, Gau ilunekoak, Donostia, Elkar.

—, 2010, Moroak gara behelaino artean?, Iruñea, Pamiela. 
